\title{
Sensitivity analysis applied to fuzzy inference on the value of information in the oil and gas industry.
}

VILELA, M., OLUYEMI, G., PETROVSKI, A. 


\title{
Sensitivity analysis applied to fuzzy inference on the value of information in the oil and gas industry
}

\author{
Martin Vilela, Gbenga Oluyemi and Andrei Petrovski \\ Robert Gordon University \\ Sir Ian Wood Building, Garthdee Road, Aberdeen, AB10 7QB \\ Scotland, UK \\ \{m.j.vilela-ibarra, g.f.oluyemi, a.petrovski\}@rgu.ac.uk
}

\begin{abstract}
Value of information is a widely accepted methodology for evaluating the need to acquire new data in the oil and gas industry. In the conventional approach to estimating the value of information, the outcomes of a project assessment relate to the decision reached by following Boolean logic. However, human thinking is based on a more complex logic that includes the ability to process uncertainty. In value of information assessment, it is often desirable to make decisions based on multiple economic criteria which, if independently evaluated, may suggest opposite decisions. Artificial intelligence has been used successfully in several areas of knowledge, increasing and enhancing analytical capabilities. This paper aims at enriching the value of information methodology by integrating fuzzy logic into the decision-making process; this integration makes it possible to develop a human thinking assessment and coherently combine several economic criteria. To the authors' knowledge, this is the first use of a fuzzy inference system in the specified knowledge domain. The methodology is successfully applied to a case study of an oil and gas subsurface assessment where the results of the standard and fuzzy methodologies are compared, leading to a more robust and complete evaluation. Sensitivity analysis is undertaken for several membership functions used in the case study to assess the impact that shifting, narrowing and stretching the membership relationship has on the value of information. The results of the sensitivity study show that, depending on the shifting, the membership functions lead to different decisions; additional sensitivities to the type of membership functions are investigated, including the functions’ parameters.
\end{abstract}

Keywords: Value of information, fuzzy inference system, sensitivity analysis, oil and gas industry, uncertainty.

Reference to this paper should be made as follows: Vilela, M., Oluyemi, G.F. and Petrovski, A. (xxxx) 'A fuzzy inference system applied to value of information assessment for oil and gas industry”, Int. J. of Applied Decision Sciences, Vol. X, No. Y, pp.xxx-Xxx.

Biographical notes: Martin Vilela is a physicist with a long experience on reservoir analysis and operations and dynamic simulation. His research interest includes subsurface characterization and description, wells and field performance, uncertainty quantification and decision making.

Gbenga Folorunso Oluyemi is a Lecturer from the School of Engineering, Robert Gordon University, Aberdeen. His research interests cover areas such as rock geomechanics, oilfield chemistry, flow assurance and uncertainty analysis. He is a Chartered Engineer in the UK and a Fellow of the UK HEA. He holds a $\mathrm{PhD}$ in Petroleum Geomechanics.

Andrei Petrovski is a Reader at Robert Gordon University, Aberdeen, UK. His research expertise includes computational modelling, optimisation and decision support. He is also interested in practical application of cloud and mobile computing, as well as computer-assisted measurements. He uses these technologies for improving versatility of information systems and for adding intelligent features to these systems. This has led to the publication of over 60 peer-reviewed papers including a book chapter, journal and conference articles in the field of computational intelligence, control systems, medical informatics and decision support. Application domains of his research include oil and gas industry, medicine and health informatics, and electrical power systems. 


\section{INTRODUCTION}

\subsection{The value of information concept}

Value of information (VoI) is a prescriptive methodology embedded in the discipline of decision analysis that is focused on assessing the value associated with gathering information. To that end, the methodology maximizes an objective function, which defines the value of a project.

Grayson (1960), Raiffa and Schlaifer (1961) and Newendorp (1967) were the pioneers in the field of decision making for data acquisition in the oil and gas industry. Subsequently, more research and applications, such as those of Warren (1983), Lohrenz (1988), Demirmen (1996), Newendorp and Schuyler (2000) and Koninx (2000), among others, expanded the scope of the subject, adding more robustness to the methodology.

Recently, more applications have emerged-like those of Clemen (1996), Coopersmith and Cunningham (2002), Begg et al. (2002) who discussed the use of the value of flexibility as a complementary methodology to VOI for assessing the value of uncertain projects, Suslick and Schiozer (2004)—which enrich the process of assessing the VoI decision problem from a methodological perspective. Several papers, such as those by Walls (2005) and Vilela, Oluyemi and Petrovski (2017), have discussed the use of utility theory in the VoI assessment in the oil and gas industry. In unconventional reservoirs, Bickel (2014) applied decision analytics and value of information methodologies. The flexibility of the VoI methodology for application in real time is shown by Kullawan et al. (2014) in a geosteering application during a drilling operation. VoI has been applied on expensive and complex projects such as 4D seismic acquisition, as shown by Ferreira (2015) using a probabilistic approach. Grose and Smalley (2017) discussed a risk-based surveillance planning method that uses the methodology of VoI in producing oil fields. For fracture reservoirs under waterflooding, Shbair et al. (2017) discussed the application of VoI for reservoir surveillance. In enhanced oil recovery (EOR) applications, VoI has been used for assessing the value of a pilot project of polymer injection, as discussed by Steineder et al. (2018) for a horizontal well.

On occasions, additional data can be acquired to change the uncertainty in the reservoir parameters; however, acquiring data involves a cost that could be greater than the benefits of the data. Changes in the reservoir parameters' uncertainties translate to changes in the value of the project. In general, acquiring additional data makes sense in cases when the outcome from the data acquisition can change the decisions being made.

For a project with uncertain outcomes, the VoI is the difference between the expected value (EV) of the project with and without the newly acquired data (Bratvold et al., 2007):

$V O I=E V_{\text {with information }}-E V_{\text {without information }}$

where both values, $E V_{\text {with }}$ information and $E V_{\text {without information }}$, assess the outcome of the project in these circumstances and refer to a future situation.

In the 'without-information' case, for $\kappa$ possible scenarios, the EV of the project corresponding to the $j^{\text {th }}$ scenario is defined as:

$E V\left(a_{j}\right)=\sum_{i=1}^{n} u_{j i} p\left(s_{i}\right)$

where $u_{j i}$ is the value of the state of nature $s_{i}$ for the scenario $a_{j}$ and $p\left(s_{i}\right)$ is the prior probability of the state of nature $s_{i}$. The most often used decision criterion is to select the alternative that maximizes the EV:

$E V\left(a^{*}\right)=\underset{j}{\max E V\left(a_{j}\right)}$

Equation (3) is the $E V_{\text {without information }}$ term shown in Equation (1).

Similarly, in the 'with-information' alternative, for $\kappa$ possible scenarios and for each possible data outcome, $x_{k}$, the EV for the $j^{t h}$ alternative is:

$E V\left(a_{j} \mid x_{k}\right)=\sum_{i=1}^{n} u_{j i} p\left(s_{i} \mid x_{k}\right)$

where $u_{j i}$ is the value of the state of nature $s_{i}$ for the scenario $a_{j} ; p\left(s_{i} \mid x_{k}\right)$ is the posterior probability of the state $s_{i}$ given the outcome $x_{k}$; and the term $E V\left(a_{j} \mid x_{k}\right)$ is the expected project value for the $j^{\text {th }}$ alternative given the outcome $x_{k}$.

Similarly, as in the 'without-information' case, the optimum alternative in the 'with-information' case for a given data outcome $x_{k}$ (EV conditioned on the outcome $\left.x_{k}\right)$ is the one that maximizes the EV:

$E V\left(a^{*} \mid x_{k}\right)=\underset{j}{\max E V\left(a_{j} \mid x_{k}\right)}$ 
The unconditional maximum EV is the sum of the conditional EV weighted with the corresponding marginal probabilities:

$E V\left(a^{*}\right)=\sum_{k=1}^{n} E V\left(a^{*} \mid x_{k}\right) p\left(x_{k}\right)$

The VoI is the difference between the estimates of EV in Equation (6) and Equation (3).

\subsection{Review fuzzy logic}

Fuzzy logic, pioneered by Zadeh (1965), is one of the most prolific areas of artificial intelligence, which has enriched the analysis of challenging and complex problems. Bellman and Zadeh (1970) introduced an important distinction between randomness and fuzziness: while randomness relates the uncertainty concerning membership or non-membership of an object or event to a non-fuzzy set (a crisp set), fuzziness deals with classes in which there may be degrees of membership.

In recent years, fuzzy logic has been applied on several problems in the oil and gas industry, as by Ebrahimi and Sajedian (2010), who developed a method for predicting the two-phase inflow performance relationship of horizontal oil wells. Kobrunov, Kuleshov and Mogutov (2012) used a fuzzy petrophysical compositions method for calculating hydrocarbon reserves. Popa (2013) discussed the optimum horizontal well placement using fuzzy logic, working with electric submersible pumps. Bermudez et al. (2014) developed a methodology for the monitoring and prediction of unexpected behaviour. Mirzabozorg et al. (2014) developed a methodology using fuzzy logic for the integration of engineering knowledge during history matching performance. Nashawi and Malallah (2015) used fuzzy logic for wireline well logs permeability prediction. Nageh (2015) developed a screening criterion for EOR technologies using artificial intelligence techniques. Thong and Kepic (2015) developed fuzzy clustering techniques for incorporating prior information into seismic impedance inversion. Sari (2016) used fuzzy logic for estimating the rock strength. Bukhamseen et al. (2016) built a streamlined model guided by fuzzy logic to optimize field injection and production strategies. Grassian et al. (2017) discussed a fuzzy expert system for the analysis and optimization of electric submersible pumps failure modes. Passalacqua and Qubian (2018) developed a decision-making approach for heavy oil field projects using a fuzzy analytical hierarchy process, and Ahmed et al. (2019) used fuzzy logic for the prediction of the rate of penetration during drilling in a shale formation.

In the standard VoI approach, once the different alternatives for the project are assessed, the decision ("the project is viable to endorse", "the project is unviable to endorse" or "the project needs reframing") is made using crisp criteria that do not correspond with human fuzzy thinking for making decisions. Following Bellman and Zadeh (1970), the uncertainty related to fuzziness is a major source of uncertainty in many decision processes.

In classical set theory, the events (values) belong (or not) to sets in a crisp manner that is represented by the "characteristic function", defined by Equation (7), which is a mapping from the input variables to the Boolean set $\{0,1\}$ :

$\mu_{M}= \begin{cases}1, & x_{k} \in M \\ 0, & \text { otherwise }\end{cases}$

Thus, an event (e.g. X) belongs totally or not at all (1 or 0 ) to a set; these kinds of relationships follow Boolean logic.

As a practical example, in subsurface reservoirs, the characteristic function allows establishing a Boolean relationship ( 1 or 0 , i.e. totally belongs or totally excluded) between quantitative input variables (e.g. reservoir depth of $5000 \mathrm{ft}$ ) and descriptive terms (e.g. deep reservoir). Fuzzy logic extends the mapping between events and sets using the Membership Functions (MFs) to include all the values between 0 and 1 , $[0,1]$. The membership values measure the degree of belonging of each event to a given set, representing the "degree of membership" of the mentioned event to that set. In this logic, an event (e.g. reservoir depth of $5000 \mathrm{ft}$ ) belongs partially (with a value between 0 and 1) to a set (e.g. deep reservoir).

In practice, fuzzy logic is implemented through a process called a "fuzzy inference system" (FIS). A FIS is a procedure that derives its output based on fuzzy reasoning and a set of IF-THEN rules using MFs. The FIS performs approximate reasoning like the human brain, albeit in a much more straightforward manner.

The FIS is one of the most prolific applications of fuzzy logic. It has been used recently in very different areas and within various problem domains, such as: the assessment of water quality in rivers (Ocampo, 2008), the improvement of image expansion quality (Sakalli, Yan and Fu, 1999), the differential diagnosis of nontoxic thyropathy (Guo and Ling, 2008), the development of a fuzzy logic controller for a traffic junction (Pappis and Mamdani, 1997), maintenance scheduling of Smart Grid systems (Malakhov et al, 2012), the design of fire monitoring sensors in coal mines using fuzzy logic (Muduli, Jana and Mishra, 2017), the estimation of the impact of tax legislation reforms on the tax potential (Musayev, Madatova and Rustamov, 2016), pipeline risk assessment (Jamshidi et al., 2013), depression diagnosis (Chattopadhyay, 2014), river 
discharge prediction assessments (Jayawardena et al., 2014), geological strength index calculation and slope stability assessments (Sonmez, Gokceoglu and Ulusay, 2004), the regulation of industrial reactors (Ghasem, 2006) and the use of a fuzzy logic approach for file management and organization (Gupta, 2011).

From a methodological perspective, the FIS can be understood as a general procedure that transforms a set of input variables into a set of outputs, following the workflow shown in Figure 1.

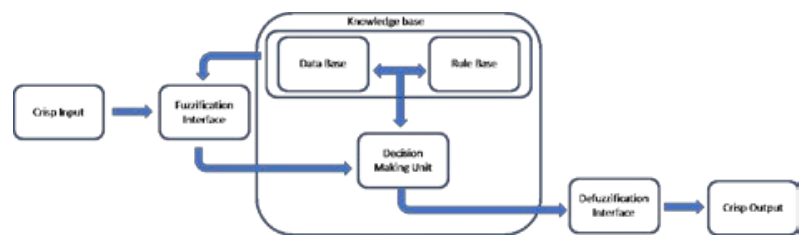

Figure 1. Fuzzy inference system

For a Mandani FIS, shown in Figure 1, the outcome is a crisp number, independently of the number of crisp parameters used the asses the value of the project (e.g. NPV, DPI, IRR, etc.).

\section{APPLICATION}

\subsection{Reservoir description}

An exploration campaign conducted in Algeria discovered a medium-sized oil field located at $5200 \mathrm{ft}$. TVD SS. Four wells were drilled. The operator's technical team has estimated that the main source of subsurface uncertainty is the well productivity.

Based on the information gathered during the exploration phase and from similar fields in the same basin, a material balance model is built to represent the forecast oil rate for the high-, medium- and lowdevelopment scenarios, as shown in Figure 2.

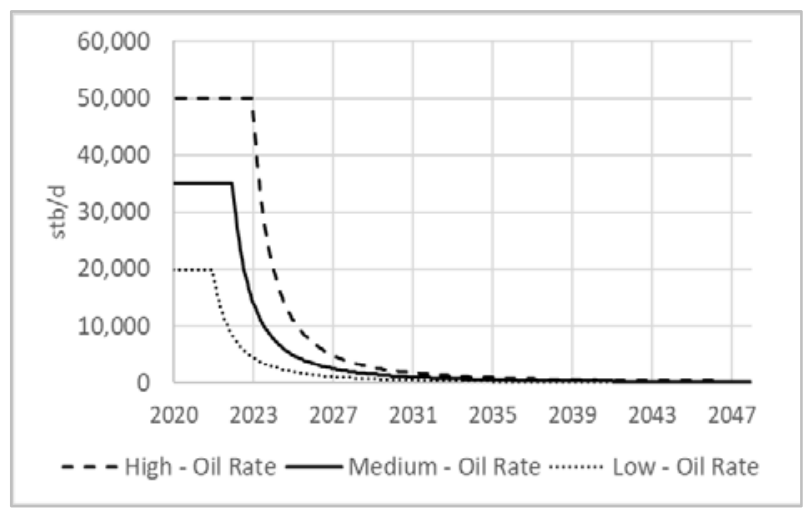

Figure 2. The oil production rate scenarios

\subsection{Problem specification}

At this stage, the operator company must decide whether acquiring additional information would increase the project's value.

Alternative A: without-information. The decision on project development is made based on the current information using the expected value (EV) of the net present value (NPV) and the discounted profit to investment ratio (DPI).

Alternative B: with-information. Additional information is acquired regarding the uncertain parameters of the reservoir and, subsequently, based on the outcomes of the data obtained, a decision is made on the future development of the project.

The NPV is the yearly net cash flow discounted to the weighted average cost of capital (WACC) which in this case is $10.5 \%$; the DPI is the result of dividing the discounted net cash flow by the discounted sum of the investment using the WACC.

The outcome of the assessment will result in one of the following options:

1) the project is viable to endorse it will proceed to the development phase, which necessitates a large capital investment;

2) the project is not viable to endorse it will be relinquished, carrying the losses associated with the exploration costs; 
3) the project needs additional analysis before deciding it will be reframed.

\subsection{Classical VoI assessment}

In this section, the classical approach to the VoI is discussed.

\subsubsection{Decision rules}

Based on the operator's portfolio of projects, the criterion for making decisions on projects with a financial investment higher than US\$500 million is: A) a project with NPV lower than US\$100 million is unviable to endorse, B) a project with NPV higher than US\$500 million is viable to endorse and, C) a project with NPV between US\$100 million and US\$500 million is reframed to find alternative development options.

Regarding the DPI: A) a project with DPI higher than 0.5 is viable to endorse, B) a project with DPI lower than 0.0 is unviable to endorse and, C) a project with DPI between 0.0 and 0.5 should be reframed.

\subsubsection{VoI assessment for the without and with-information alternatives}

For the without-information and with-information alternatives, Table 1 shows the calculated expected value for NPV (EVNPV) and DPI (EVDPI)

Table 1. Expected values for NPV and DPI for the without-information and with-information alternatives

\begin{tabular}{|l|c|l|}
\hline \multicolumn{1}{|c|}{ Criterion } & Value & Decision \\
\hline $\begin{array}{l}\text { Without-information } \\
\text { EVNPV (US\$ mm) }\end{array}$ & 479 & Reframed \\
\hline $\begin{array}{l}\text { With-information } \\
\text { EVNPV (US\$ mm) }\end{array}$ & 537 & Endorsed \\
\hline $\begin{array}{l}\text { Without-information } \\
\text { EVDPI (fraction) }\end{array}$ & 0.52 & Endorsed \\
\hline $\begin{array}{l}\text { With-information } \\
\text { EVDPI (fraction) }\end{array}$ & 0.44 & Reframed \\
\hline
\end{tabular}

Summarizing: using NPV and DPI the alternatives that maximize the value are the with-information and the without-information respectively.

At this stage, using two financial criteria, we have two contrasting recommendations about the future of the project.

Making a decision using these crisp criteria does not include the sophisticated elements used by human thinking in which, the criteria may overlap.

\subsection{FIS value of information assessment}

Up to this stage, the criterion to decide the future of the project has been based on linguistic variables like "not endorse”, “endorse”, “viable”, “unviable”, "high”, “medium” and "low”; fuzzy logic can be utilized advantageously to assess projects that used these variables.

\subsubsection{FIS building and application}

The MFs are chosen because they capture the technical team members' interpretation of the degree to which the NPV and DPI figures belong to the three categories into which the range of potential values are divided; in this case study we use triangular MFs.

The comparison between the output of the FIS for the with-information and that for the withoutinformation alternative indicates which alternative has more value.

A Mamdani FIS with the centroid defuzzification method was used in this assessment. Figure 3 shows the design of the FIS using MATLAB. The MFs used in this case study for NV, DPI and the decision are shown in Figures 3, 4 and 5. 


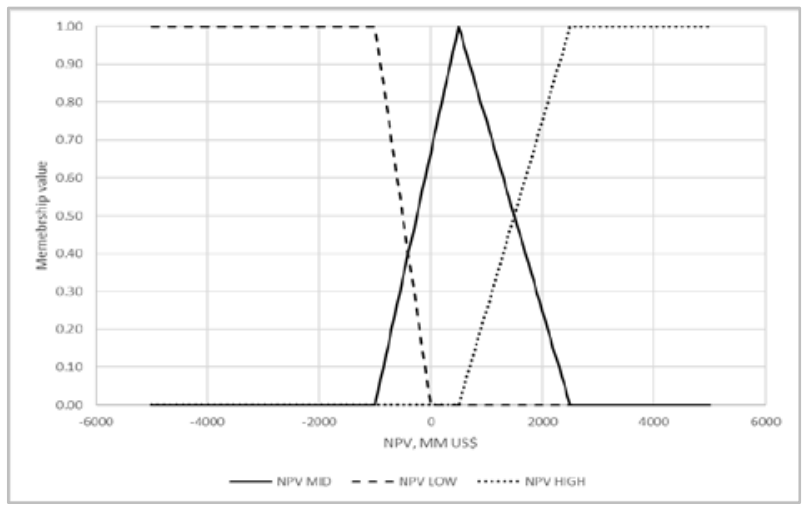

Figure 3. Membership Function for NPV (input)

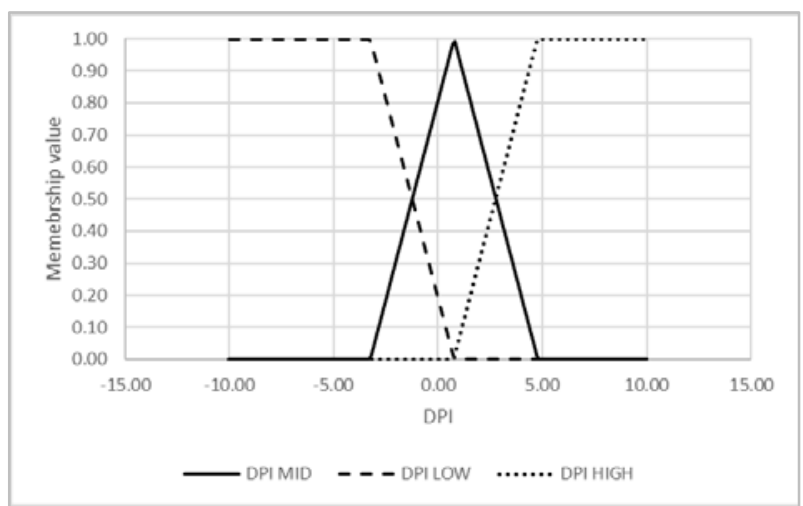

Figure 4. Membership Function for DPI (input)

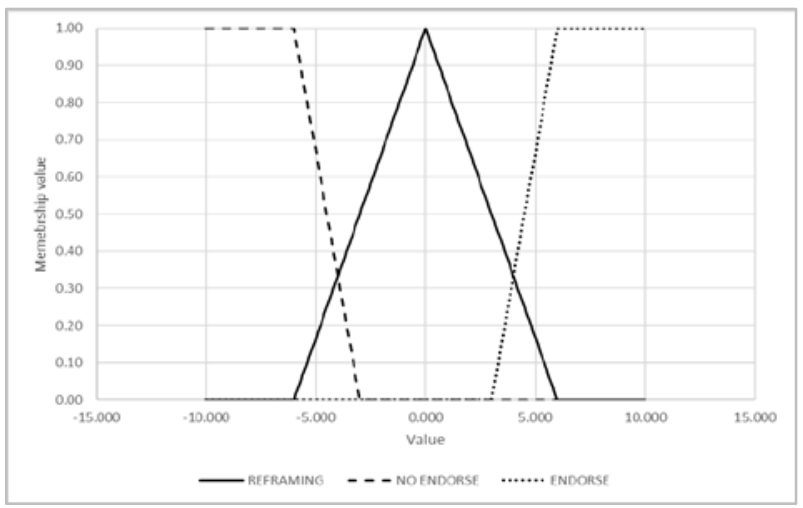

Figure 5. Membership Function for the decision (output)

The decision rules indicate the manner in which the two fuzzy financial parameters combine to result in a fuzzy decision. In this work we define the rules shown in Table 2 to include the cases of interest 
Table 2. Decision rules

\begin{tabular}{|c|c|c|}
\hline RULES & IF & THEN \\
\hline Rule 1 & $\begin{array}{c}\text { (NPV is NPV_HIGH) } \\
\text { ( (DPI is DPI_HIGH) }\end{array}$ & ENDORSE \\
\hline Rule 2 & $\begin{array}{c}\text { (NPV is NPV_HIGH) } \\
\text { ( (DPI is DPI_MID) }\end{array}$ & ENDORSE \\
\hline Rule 3 & $\begin{array}{c}\text { (NPV is NPV_HIGH) } \\
\text { ( (DPI is DPI_LOW) }\end{array}$ & REFRAMING \\
\hline Rule 4 & $\begin{array}{c}\text { (NPV is NPV_MID) } \\
\text { (DPI is DPI_LOW) }\end{array}$ & REFRAMING \\
\hline Rule 5 & $\begin{array}{c}\text { (NPV is NPV_LOW) } \\
\text { (DPI is DPI_LOW) }\end{array}$ & NO_ENDORSE \\
\hline Rule 6 & $\begin{array}{c}\text { (NPV is NPV_LOW) } \\
\text { (DPI is DPI_HIGH) }\end{array}$ & REFRAMING \\
\hline Rule 7 & $\begin{array}{c}\text { (NPV is NPV_MID) } \\
\text { (DPI is DPI_MID) }\end{array}$ & ENDORSE \\
\hline
\end{tabular}

The rationale for the selection of these MFs is that, for very high or very low NPV values, the NPV belongs to only one set, the NPV_HIGH or the NPV_LOW, with a membership value of 1 ; for the intermediate NPV value, the NPV belongs partially to the three fuzzy sets. This fuzzy representation of the criteria for categorizing the project is based on past decisions made by the field operator company. The selection of the MFs needs to be updated once more decisions have been taken.

The MFs for the DPI are chosen following the same procedure used for the NPV

The authors define a set of seven rules that determine the logic of this decision; these rules (IF-THEN rules) are made by pairs of NPV and DPI figures and a consequential sentence (THEN). The rules do not pretend to be exhaustive but must be coherent. All the rules were built using the AND connector; although, in general, they can be defined equally well with OR.

\subsubsection{FIS applied to the without and with -information alternatives}

Referred to Section 1.2, the outcome of FIS (a crisp number) is the value of the project resulting from aggregating the project's values in terms of NPV and DPI; in addition, the FIS assessment includes the imprecision in the terms used to decide whether a project worth or not to endorse (Section 2.2).

For evaluating the project using the FIS developed in Section 2.4.1, the crisp values for NPV and DPI estimated in Section 2.3.2 Table 1 (US\$479 million and 0.52), are input in the FIS; the outcome of the assessment made by the FIS indicates that the value associated with the without-information alternative is $\underline{7.2}$.

Similarly, in the with-information alternative, the NPV and DPI figures (US\$537 million and 0.44), contained in Table 1, are input in the FIS; as a result, the FIS assessment for the with-information alternative is $\underline{\mathbf{6 . 9 7}}$.

Since, the value of the FIS for the without-information alternative is higher than the value of the FIS for the with-information case, the best alternative for the decision problem discussed is to endorse the project now and move it forward to the development phase without acquiring additional data.

This result means that, although the data acquisition reduces the uncertainty regarding well deliverability, the cost of this data acquisition (additional investment and oil production delay), is higher than the increased project value due to uncertainty reduction.

\section{SENSITIVITY}

The MFs have been chosen based on the authors' experience and the operator decision rules (Section 2.3.1); here we develop a sensitivity study to capture the impact that modifications in the MFs may have on the decision; the sensitivity study includes three cases: A) shifting the triangular MFs for NPV and DPI, B) narrowing and stretching the triangular MFs, and C) replacing the triangular MFs by the sigmoidal MFs. 


\subsection{Shifting the triangular MFs}

The MFs can be shifted to the right (towards positive NPV numbers) or to the left (towards negative NPV numbers) compared with the study case described in Figure 3 Section 2.4.1; Figures 6 and 7 show shifting by US\$-2000 million and US\$+2000 million

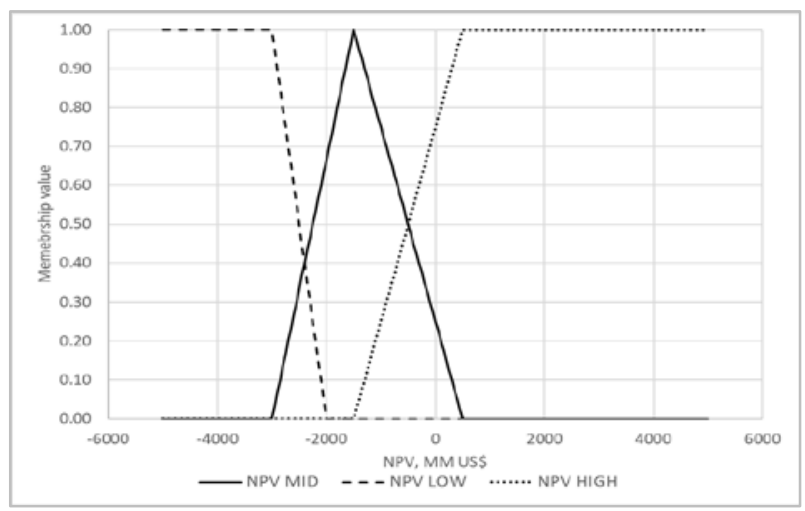

Figure 6. MFs shifted to the left by US\$ -2000 million

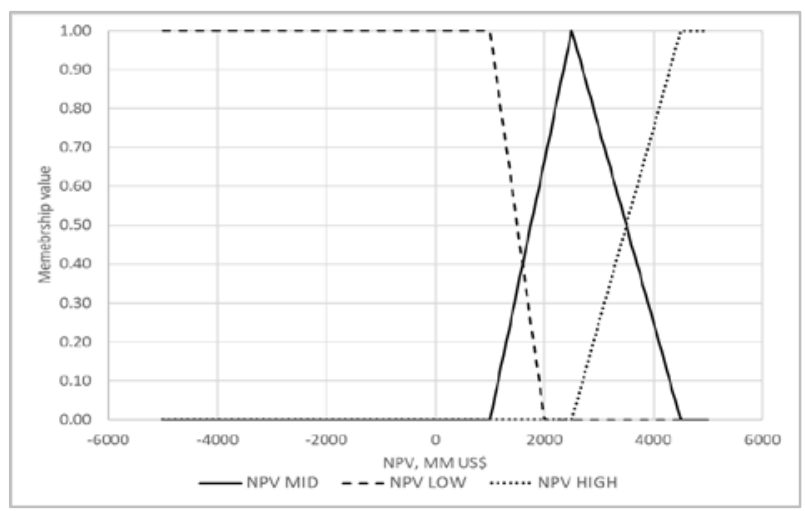

Figure 7. MFs shifted to the left by US\$ +2000 million

Similarly, to the NPV, a shifting is applied to the MFs describing the DPI.

The best decision using the original MFs is the without-information alternative.

Based on the sensitivity analysis, Figure 8 shows that when shifting to the left by any value or to the right by a maximum of US\$ + 250 million, the best decision remains the without-information alternative; however, shifting the MFs to the right by US\$ +500 million or more swaps the decision to the with-information alternative.

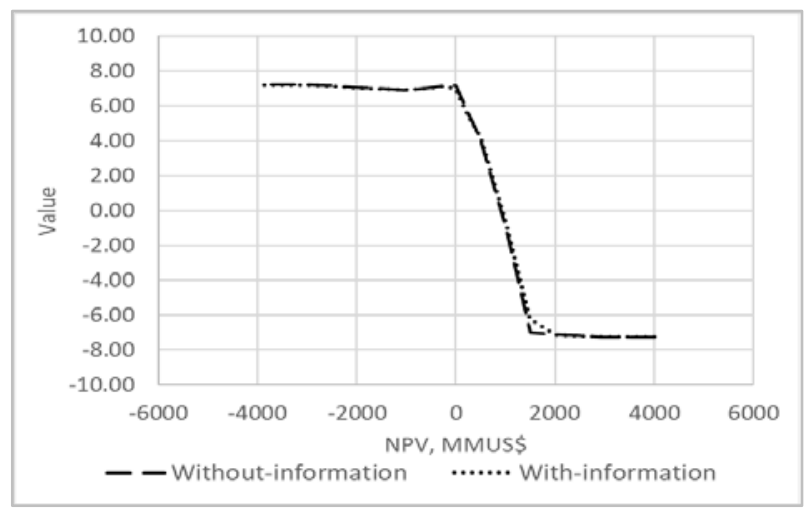

Figure 8. Variation in project value while shifting the MFs

It is observed that the differences between the without-information and with-information acquisition alternatives are small which is related with the fact that the NPV and DPI values of the two alternatives are also small (US\$ 537 million and 479 million for NPV and 0.44 and 0.52 for DPI).

This analysis shows that, for shifting to the right higher than US\$ +3000 million or to the left lower than US\$ -3000 million, both alternatives, without-information and with-information are equally desirable. 


\subsection{Narrowing and stretching the triangular MFs}

Narrowing or stretching the MFs has the effect of reducing or increasing the imprecision of the criteria to make decisions.

Figures 9 and 10 show the narrowing (by US\$-800 million) and stretching (by US\$+800 million) of the MFs with respect to the MF (Figure 3) used in the decision assessment (Section 2.4.2)

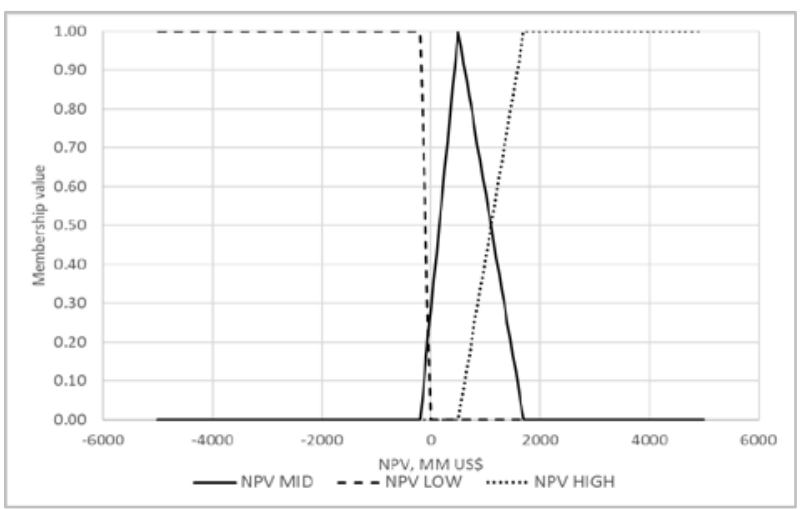

Figure 9. MFs narrowed by US\$ +800 million

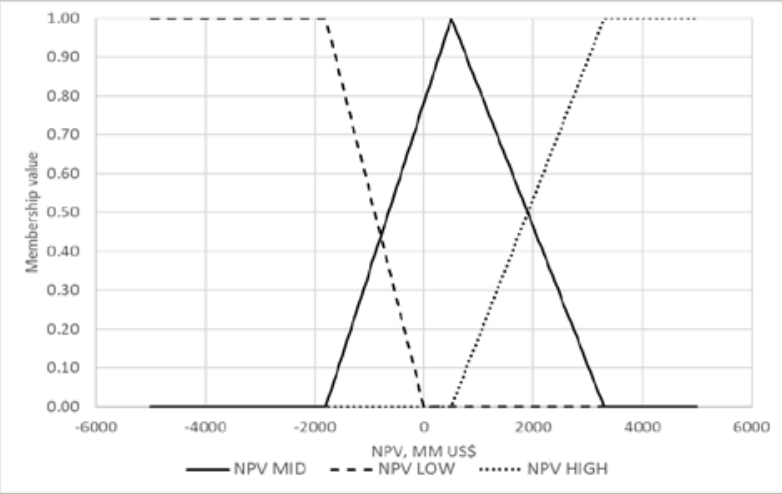

Figure 10. MFs stretched by US\$ -800 million

Using different levels of narrowing and stretching of the MFs, both for NPV and DPI, has an impact on the value of the assessment as shown in Figure 11

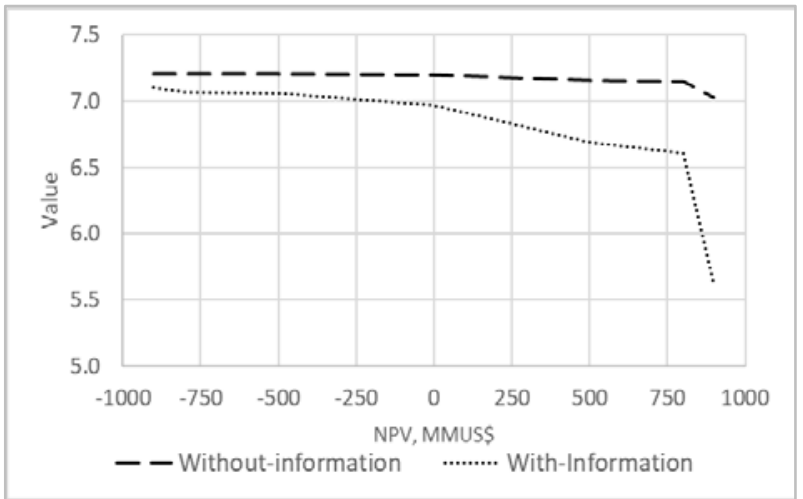

Figure 11. Variation in project value when narrowing and widening the MFs

The zero ("0") NPV, the reference case, corresponds to the MFs used in the case study; to the right of the reference (positive NPV) corresponds to narrowing the MFs and to the left of the reference (negative NPV) corresponds to stretching the MFs; it is observed that stretching the MFs has the effect of increasing the value of the project while narrowing the MFs decreases the value of the project.

In the case study, discussed in Section 2.4.2, the without-information alternative has a higher value than the with-information alternative; this result holds for all the sensitivities tested, although the difference between alternatives reduces as the MFs are stretched and increases when the MFs are narrowed. 


\subsection{Replacing the triangular MFs by the sigmoidal MFs}

In this case, the triangular MFs are replaced by sigmoidal MFs; sigmoidal MFs have a nonlinear form in contrast to triangular MFs. Figure 12 shows the sigmoidal MFs used NPV

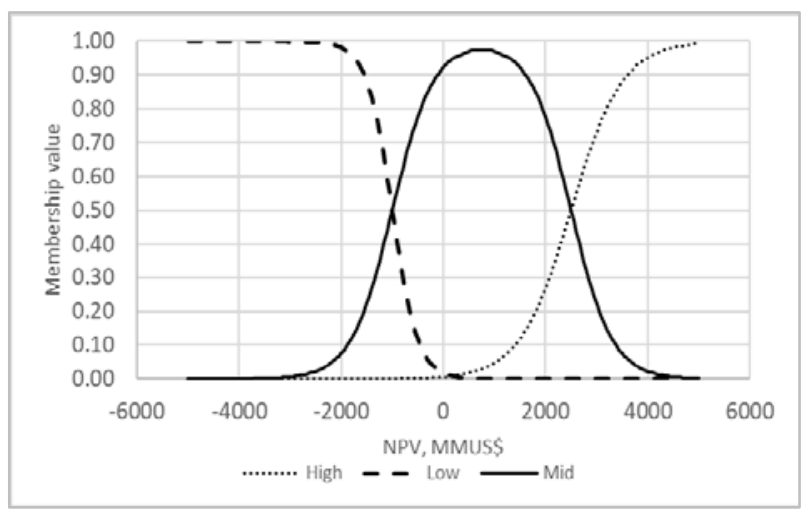

Figure 12. Membership functions for the NPV using sigmoidal functions

Similar MFs are used to model the DPI and the decisions.

The sigmoidal function is used to represent processes that change slowly for low values then increase very fast for a short range until reaching an asymptotic value; these processes are characterized by the "S" shape of the sigmoidal function.

In this analysis, the slope and the crossover point of the sigmoidal functions are selected to mimic, as closely as possible, the characteristics of the previous triangular MFs, but replacing the linear trend of the triangular functions with the non-linear trend in the sigmoidal functions.

In this case study, the result of both alternatives, using the sigmoidal MF for without-information and with-information produces the same value: 7.68. This assessment contrasts with the one using triangular MFs, which show that the without-information is a better decision than the with-information alternative.

Additional sensitivity analysis is done, changing the slope of the functions, while keeping the crossover points; the results are shown in Figure 15.

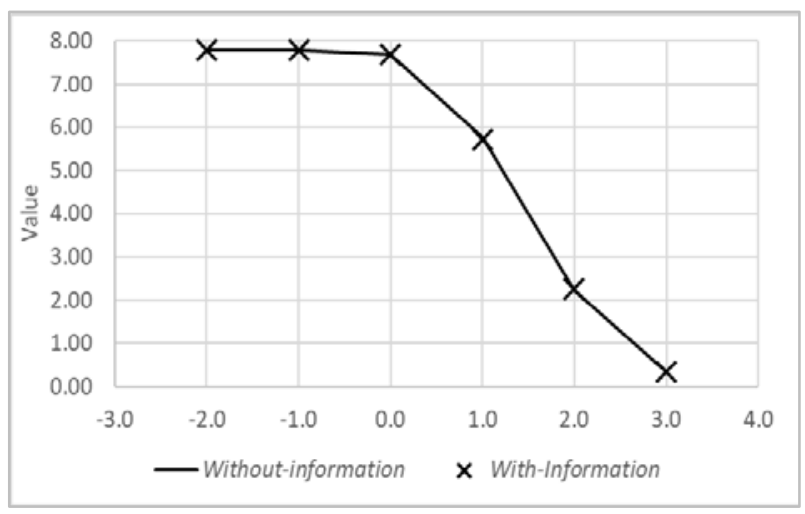

Figure 15. VoI using sigmoidal membership functions

In Figure 15, the vertical axis is the FIS assessment and the horizontal axis represents the changes in the slope of the sigmoidal function, where " 0 " is the case shown in Figures 12 and 13; " 1 " is the assessment resulting from using $1 / 2$ the slope of case " 0 "; " 2 " $1 / 4$ the slope of case "0",etc. and "- 1 " is the assessment using the slope of " 0 " multiplied by 2 , and "-2" is the assessment using the slope of " 0 " multiplied by 4.

\section{CONCLUSIONS AND FUTURE WORK}

In this study, an FIS has been successfully implemented with the aim of assessing the VoI of an oil and gas project. In the discussed case study, the use of the FIS was able to introduce the fuzzy thinking of the decision maker into a subsurface VoI assessment while removing ambiguity coming from the use of more than one economic parameter for decision making. 
The proposed methodology for VoI assessment using FIS has improved the conventional approach because:

A) instead of using a Boolean relationship between the project valuation and project decision, the FIS uses a fuzzy human thinking approach to make decisions;

B) the FIS uses a coherent method to integrate more than one criterion into the assessment, while, in the conventional VoI approach, when more than one criterion is used, they can reach contradictory outcomes which lead to an inconclusive assessment.

In addition to the aspects discussed above, the FIS provides a tool for "self-learning", in which the quality of the VoI assessments can be improved through continuous updating of the decision-making unit, knowledge base, and fuzzification and defuzzification interfaces with actual decisions, progressively generating a more robust FIS and making the system act closer and closer to the way in which humans make decisions. The FIS brings the VoI methodology closer to the decision maker's reasoning.

In summary, the use of the FIS makes it possible to have a system that can integrate the linguistic variables that are part of human language, reasoning, and understanding, but not necessarily part of the Boolean logic used in the standard VoI, into the prescriptive VoI assessment.

VoI assessment using the FIS brings the decision-making process one step forward with respect to the classical VoI approach. To have tools and methods that replicate the human reasoning process for assessing VoI increases the confidence of the decision maker in those procedures, thereby increasing their use and making the tools more reliable.

Decisions are made by humans, and because human thinking is approximated more accurately by imprecise logic than by crisp logic, this research work successfully develops a methodology that integrates human logic in the VoI assessment, especially for problems in the oil and gas industry; the integration of the imprecise thinking and terminology in the VoI is done using FIS.

In our case study, the NPV and DPI values of the without-information and with-information cases are very close; this made it difficult to assess the impact of variations on the selected MFs. It is suggested to make a similar analysis in a case where the differences are larger.

The impact of selecting different types of MFs on the VoI assessment should also be further investigated.

The impact that the ranges and spread of the MFs have on the decision assessment is of utmost importance to be able to provide robust and consistent decisions.

\section{MANAGERIAL SIGNIFICANCE}

During the decision making process, the management in the oil and gas industry does not follow a Boolean logic, i.e. based on yes or no, positive or negative, 1 or 0 , but a continuous logic as per human reasoning, i.e. based on multiple values and characterized by imprecise terms such as high, short, good. The current VoI methodology uses Boolean logic; in this paper, a VoI methodology that follows human reasoning is developed and this is carried out using FIS.

The degree to which a value belongs to the imprecise variables is defined by the membership functions; we acknowledge that the membership functions are chosen subjectively, which makes it important to assess the impact that different membership functions can have on the VoI; this assessment can be made through sensitivity analysis of the different functional forms and shapes of the membership functions, capturing the impact that changes in the selected functions have on the decision assessment.

Very often more than one decision criterion is used (or it is desirable to be used) to assess a decision because different decision criteria measure different aspects of the same decision. As it has been discussed in this paper, decisions may be different when different criteria are independently evaluated, which makes it difficult to reach a unique result for a decision problem. FIS makes it possible to aggregate several criteria into one, facilitating the decision-making process.

The methodology developed in this paper can be adapted and used for any problem of VoI in the oil and gas industry when there is imprecision in the decision terms; this methodology can closely follow human reasoning and allow meaningful decisions regarding VoI assessment to be reached. 


\section{REFERENCES}

Ahmed, A., Elkatatny, S., Ali, A., Mahmoud, M. and Abdulraheem, A. 2019. Rate of penetration prediction in shale formation using fuzzy logic. In: International Technology Conference, Beijing, China, 26-28 March. IPTC-19548-MS.

Begg, S., Bratvold, R. and Campbell, J. 2002. The value of flexibility in managing uncertainty in oil and gas investments. In: Society of Petroleum Engineers, Annual Technical Conference and Exhibition, San Antonio, Texas, USA, 29 September-2 October. SPE 77586.

Bellman, R. and Zadeh, L. 1970. Decision making in a fuzzy environment. Management Science. vol. 7, no. 4, December, pp. B-141-B-164.

Bermudez, F., Carvajal, G., Moricca, G., Dhar, J., Adam, F., Al-Jasmi, A., Goel, H. and Nasr, H. 2014. Fuzzy logic application to monitor and predict unexpected behavior in electric submersible pumps. In: Society of Petroleum Engineers, Intelligent Energy Conference and Exhibition, Utrecht, the Netherlands, 1-3 April. SPE 167820-MS.

Bickel, J. 2014. Decision analytics, value of information and piloting in unconventional reservoirs. In: Society of Petroleum Engineers, Hydrocarbon Economics and Evaluation Symposium, Houston, Texas, USA, 19-20 May 2014. SPE 169841-MS.

Bratvold, R., Bickel. J. and Petter, H. 2007. Value of information in the oil and gas industry: past, present, and future. In: Society of Petroleum Engineers, Annual Technical Conference and Exhibition, Anaheim, California, USA, 11-14 November. SPE 110378.

Bukhamseen, N., Al-Najem, A., Saffar, A. and Al-Ghareeb, Z. 2016. Streamline information guided by fuzzy logic to optimize field injection/production strategies. In: Society of Petroleum Engineers. Kingdom of Saudi Arabia Technical Symposium and Exhibition, Dammam, Saudi Arabia, 25-28 April. SPE 182742MS.

Chattopadhyay, S. 2014. A neuro-fuzzy approach for the diagnosis of depression. Applied Computing and Informatics. vol. 13, pp. 10-18.

Clemen, R. 1996. Making hard decisions. 2nd ed. California, USA: Duxbury Press.

Coopersmith, E.M. and Cunningham, P.C. 2002. A practical approach to evaluating the value of information and real option decisions in the upstream petroleum industry. In: Society of Petroleum Engineers Annual Technical Conference and Exhibition, San Antonio, Texas, USA, 29 September-2 October. SPE 159587

Demirmen, F. 1996. Use of value of information concept in justification and ranking of subsurface appraisal. In: Society of Petroleum Engineers, Annual Technical Conference and Exhibition, Denver, Colorado, USA, 6-9 October. SPE 36631.

Ebrahimi, E. and Sajedian, A. 2010. Use of fuzzy logic for predicting two-phase inflow performance relationship of horizontal oil wells. In: Society of Petroleum Engineers, Trinidad and Tobago Energy Resources Conference, Port Spain, Trinidad, 27-30 June. SPE 133436.

Ferreira, C. 2015. A probabilistic approach to quantify the value of information of 4D seismic projects. In: Society of Petroleum Engineers, Annual Technical Conference and Exhibition, Houston, Texas, USA, 28-30 September. SPE 178731-STU.

Ghasem, N. 2006. Design of a fuzzy logic controller for regulating the temperature in industrial polyethylene fluidized bed reactor. Chemical Engineering Research and Design. vol. 84, no. A2, pp. 97106.

Grassian, D., Bahatem, M., Scott, T. and Olsen, D. 2017. Application of a fuzzy expert system to analyse and anticipate ESP failure modes. In: Society of Petroleum Engineers, Abu Dhabi International Petroleum Exhibition and Conference, Abu Dhabi, UAE, 13-16 November. SPE 188305-MS.

Grayson, C.J. 1960. Decision under uncertainty; drilling decisions by oil and gas operators. $1^{\text {st }}$ ed. Boston, USA: Harvard University, Division of Research, Graduate School of Business.

Grose, T. and Smalley, P. 2017. Risk based surveillance planning: a practical value of information approach for data acquisition in producing fields. In: Society of Petroleum Engineers, January 2017 SPE Economics and Management, pp. 1-11. SPE 184409.

Guillaume, S. 2001. Designing fuzzy inference systems from data: An interpretability-oriented review. IEEE Transactions on Fuzzy Systems. vol. 9, no. 3, June 2001, pp. 426-443. 
Guo, Y. and Ling, J. 2008. Fuzzy Bayesian conditional probability model and its application in differential diagnosis of non-toxic thyropathy. $2^{\text {nd }}$ International Conference on Bioinformatics and Biomedical Engineering, 16-18 May, Shanghai, China. pp. 1843-1846.

Gupta, N. 2011. Fuzzy file management. $3^{\text {rd }}$ International Conference on Electronics Computer Technology (ICECT 2011), 8-10 April, Kanyakumari, India. pp. 225-228.

Kobrunov, A.I., Kuleshov, V.E. and Mogutov, A.S. 2012. Increase of certainty of calculation of hydrocarbon reserves on the basis of fuzzy petrophysical compositions method. In: Society of Petroleum Engineers. Russian Oil and Gas Exploration \& Production Technical Conference and Exhibition, Moscow, Russia, 16-18 October. SPE 162038.

Jamshidi, A., Yazdani, A., Yakhchali, S. and Khalegi, S. 2013. Developing a new fuzzy inference system for pipeline risk assessment. Journal of Loss Prevention in the Process Industries. vol. 26, pp. 197-208.

Jayawardena, A., Perera, E., Zhu, B., Amarasekara, J. and Vereivalu, V. 2014. A comparative study of fuzzy logic systems approach for river discharge prediction. Journal of Hydrology. vol. 514, pp. 85-101.

Koninx, J. 2000. Value-of-information - From cost cutting to value-creation. In: Society of Petroleum Engineers, Asia Pacific Oil and Gas Conference and Exhibition, Brisbane, Australia, 16-18 October. SPE 64390.

Kullawan, K., Bratvold, R. and Bickel, J. 2014. Value creation with multi-criteria decision making in geosteering operations. In: Society of Petroleum Engineers Hydrocarbon Economics and Evaluation Symposium, Houston, Texas, USA, 19-20 May. SPE 169849-MS.

Lohrenz, J. 1988. Net values of our information. Journal of Petroleum Technology. April, pp. 499-503.

Malakhov, A., Kopyriulin, P., Petrovski, S., Petrovski, A. 2012. Adaptation of smart grid technologies: The use of computational intelligence for reliability estimation and maintenance scheduling. Proceedings of the World Congress on Computational Intelligence (WCCI), Brisbane, Australia: FUZZ IEEE, pp. 934-39, July.

Mirzabozorg, A., Nghiem, L., Chen, Z., Yang, Ch. and Li, H. 2014. How does the incorporation of engineering knowledge using fuzzy logic during history matching impact reservoir performance prediction? In: Society of Petroleum Engineers, Heavy Oil Conference, Alberta, Canada, 10-12 June. SPE 170011-MS.

Muduli, L., Jana, P. and Mishra, D. 2018. Wireless sensor network-based fire monitoring in underground coal mines: A fuzzy logic approach. Process Safety and Environmental Protection. vol. 113, pp. 435-447.

Musayev, A., Madatova, S. and Rustamov, S. 2016. Evaluation of the impact of the tax legislation reforms on the tax potential by fuzzy inference method. Procedia Computer Science. vol. 102, pp. 507-514.

Nageh, M., Abu, M., El Tayeb, E. and Sayyouh, H. 2015. Application of using fuzzy logic as an artificial intelligence technique in screening criteria of the EOR technologies. In: Society of Petroleum Engineers, North Africa Technical Conference and Exhibition, Cairo, Egypt, 14-16 September. SPE 175883-MS.

Nashawi, I. and Malallah, A. 2010. Permeability prediction from wireline well logs using fuzzy logic and discriminant analysis. In: Society of Petroleum Engineers, Asia Pacific Oil and Gas Conference and Exhibition, Brisbane, Queensland, Australia, 18-20 October. SPE 133209.

Newendorp, P. 1967. Application of utility theory to drilling investment decisions. PhD dissertation. Department of Engineering, University of Oklahoma, USA.

Newendorp, P. and Schuyler, J. 2000. Decision analysis for petroleum exploration. 2nd ed. USA: Planning Press.

Ocampo, W. 2008. On the development of decision-making systems based on fuzzy models to assess water quality in rivers. $\mathrm{PhD}$ thesis. Graduate Studies in Chemical and Process Engineering, Department of Chemical Engineering, Universitat Rovira i Virgili, Tarragona.

Pappis, C. and Mamdani, E.H. 1997. A fuzzy logic controller for traffic junction. IEEE Transactions on Systems, Man, and Cybernetics. SMC-7(10), October, pp. 707-717.

Passalacqua, H. and Qubian, A. 2018. Improving the decision making for heavy oil field development projects using the fuzzy analytical hierarchy process FAHP. In: Society of Petroleum Engineers, International Heavy Oil Conference and Exhibition, Kuwait City, Kuwait, 10-12 December. SPE 193719MS.

Popa, A. 2013. Identification of horizontal well placement using fuzzy logic. In: Society of Petroleum Engineers, Annual Technical Conference and Exhibition, New Orleans, Louisiana, USA, 30 September-2 October. SPE 166313. 
Raiffa, H. and Schlaifer, R. 1961. Applied statistical decision theory. 3rd ed. Boston, USA: Division of Research, Graduate School of Business Administration, Harvard University.

Sakalli, M., Yan, H. and Fu, A. 1999. A fuzzy-Bayesian approach to image expansion. In: Neural Networks, 1999. IJCNN'99. International Joint Conference on Neural Networks, vol. 4, pp. 2685-2689.

Sari, M. 2016. Estimating strength of rock masses using fuzzy inference system. In: R. Ulusay et al., eds. Rock Mechanics and Rock Engineering: From the Past to the Future. London: Taylor \& Francis Group, ISBN 978-1-138-03265-1.

Sonmez, H., Gokceoglu, C. and Ulusay, R. 2004. A Mamdani fuzzy inference system for the geological strength index (GSI) and its use in slope stability assessments. Paper 3B 01. In: SINOROCK2004 Symposium International Journal Rock Mechanics Mineral Science, vol. 41, no. 3, CD-ROM, (C 2004 Elsevier Ltd.

Steineder, D., Clemens, T., Osivandi, K. and Thiele, M. 2018. Maximizing value of information of a horizontal polymer pilot under uncertainty. In: Society of Petroleum Engineers, $80^{\text {th }}$ EAGE Conference and Exhibition, Copenhagen, Denmark, 11-14 June. SPE 190871-MS.

Shabair, A., Hammadi, A., Adeoye, O., Abdou, M., Saputelli, L. and Bahrini, F. 2017. The value of reservoir surveillance applications to fracture carbonates under waterflooding. In: Society of Petroleum Engineers, Abu Dhabi International Petroleum Exhibition and Conference, Abu Dhabi, UAE, 13-16 November. SPE 188192-MS.

Suslick, S. and Schiozer, D. 2004. Risk analysis applied to petroleum exploration and production: An overview. Journal of Petroleum Science and Engineering. vol. 44, no. 2, pp. 1-9.

Thong, D. and Kepic, A. 2015. Incorporating information into seismic impedance inversion using fuzzy clustering technique. In: SEG New Orleans Annual Meeting, pp. 3451-3455.

Vilela, M., Oluyemi, G. and Petrovski, A. 2017. Value of information and risk preference in oil and gas exploration and production projects. In: Society of Petroleum Engineers, Annual Caspian Technical Conference and Exhibition, Baku, Azerbaijan, 1-3 November 2017. SPE-189044-MS.

Walls, M. 2005. Corporate risk taking and performance: A 20 years look the petroleum industry. Journal of Petroleum Science and Engineering. vol. 48, pp. 127-140.

Warren, J.E. 1983. The development decision: Value of information. In: Hydrocarbon Economics and Evaluation Symposium of the Society of Petroleum Engineers, Dallas, Texas, USA, 3-4 March. American Institute of Mining, Metallurgical and Petroleum Engineers. SPE 11312

Zadeh, L. 1965. Fuzzy sets. Information and Control. vol. 8, pp. 338-352. 